\title{
LETTERS
}

\section{A recall of high-strength opioids would be harmful}

In response to Mr. Matthew Herder and Dr. David Juurlink's call for the federal minister of health to recall high-strength opioid formulations, ${ }^{1}$ I argue that the risk of injury to the health of Canadians from such a policy would be greater than any risk from these medications themselves.

In my opinion, recalling high-strength opioids would be unlikely to change opioid prescribing patterns to any great extent. It would, however, have the very real potential to increase the amount of opioids being diverted to street use by increasing the number of opioid pills being prescribed and dispensed. It would also be likely to further limit access to opioids for individuals dealing with chronic pain, without addressing their underlying dependency or the tremendous lack of access to other chronic pain therapies that exists across Canada, leaving these individuals vulnerable to seeking opioids from street sources and placing themselves at a much greater risk of overdose. Also, recalling high-strength opioids may create another barrier to increasing access to prescribed opioids as a harm-reduction measure, a necessary step in dealing with the ongoing crisis of overdose deaths from contaminated street-drug supplies.

The authors themselves cite the 2012 move to change the formulation of OxyContin, which had the unintended consequence of increasing the demand for fentanyl and creating an opportunity for the black market. I hope we have learned from this example that isolated policy initiatives to change the highly complex situations of opioid overprescribing and toxic street drugs need careful analysis given the very real risk of creating net harm.

\section{Robert A. Strang MD MHSc}

Chief Medical Officer of Health, Department of Health and Wellness, Halifax, NS

Cite as: CMAJ 2019 March 4;191:E264. doi: $10.1503 / \mathrm{cmaj} .71574$

\section{Reference}

1. Herder M, Juurlink D. High-strength opioid formulations: the case for a ministerial recall. CMAJ 2018;190:E1404-5.

Competing interests: None declared. 